\title{
EL SISTEMA DE RESPONSABILIDAD CIVIL POR DAÑOS AL CONSUMIDOR
}

THE CIVIL LIABILITY SYSTEM FOR CONSUMER DAMAGE

\section{CRISTIAN RICARDO A. PIRIS}

Facultad de Ciencias Económicas

Universidad Nacional del Nordeste

ARGENTINA

La libertad sólo es una parte de la historia y la mitad de la verdad. La libertad no es más que el aspecto negativo de cualquier fenómeno, cuyo aspecto positivo es la responsabilidad. De hecho, la libertad corre el peligro de degenerar en nueva arbitrariedad a no ser que se viva con responsabilidad. 


CRISTIAN RICARDO A. PIRIS
EL SISTEMA DE RESPONSABILIDAD CIVIL POR DAÑOS AL CONSUMIDOR
Pags. $27-46$

Recibido: 04/09/2017

Aceptado: 28/o8/2017

\title{
RESUMEN
}

E

n este trabajo veremos las razones por las cuales este segmento de la responsabilidad civil amerita soluciones jurídicas "locales" para hacer frente a sus particularidades.

Tomaremos una visión panorámica del camino recorrido por el régimen de daños al consumidor hasta su estado actual, viendo sus avances tanto en el common law como en el civil law. Por último, vamos a presentar el estado actual de la materia marcando sus propiedades caracterizantes a nivel general, es decir, sin aludir a ningún régimen jurídico en particular, para finalmente identificar tendencias que nos permitan proyectar posibles caminos de desarrollo futuro.

Palabras clave: responsabilidad civil, daños, productos elaborados, consumidor.

\begin{abstract}
In this paper we will see the reasons why this segment of civil liability merits "local" remedies to deal with its peculiarities. We will take a panoramic view of the path taken by the consumer regime damage to its present state, watching their progress both common law and civil law. Finally, we present the current state of matter marking their properties characterizing a general level, that is, without reference to any particular legal regime to finally identify trends that allow us to project possible future paths of development.
\end{abstract}

Keywords: civil liability, damages, product liability, consumer.

\section{INTRODUCCIÓN}

En el presente trabajo voy a presentar una visión panorámica del camino recorrido por el régimen de daños al consumidor desde sus orígenes hasta su estado actual, destacando la importancia que tiene éste ámbito de la responsabilidad civil, que hace cincuenta años atrás era virtualmente desconocido en el contexto del Derecho de Daños. Esa aproximación servirá de contexto para presentar el "estado del arte" en la actualidad y delinear posibles desarrollos futuros.

En primer lugar voy a circunscribir el objeto de análisis, tanto conceptual como temáticamente. En ese sentido voy a recortar un segmento de la responsabilidad civil, como es la responsabilidad por daños al consumidor y pasaré a explicar por qué motivos considero que se 
trata de un espacio jurídico "distinto", "especial”, que amerita soluciones "locales” y no le es suficiente la aplicación del régimen general del sistema de responsabilidad civil o las traspolaciones de soluciones jurídicas de otros segmentos de la responsabilidad.

En segundo lugar voy a exponer la evolución del sistema de responsabilidad en materia de daños al consumidor, sin concentrarme puntualmente en ningún derecho nacional, algunos de los cuales citaré pero solo a manera de ejemplo. Esto será posible dado que existen caracteres comunes que van a hacer aplicables los presentes análisis, virtualmente, a todo el Derecho comparado (al menos a la familia jurídica occidental) más allá de alguna particularidad puntual.

Finalmente, voy a presentar el estado actual de la materia e identificar tendencias que permitan proyectar posible caminos de desarrollo futuro.

\section{DELIMITACIONES CONCEPTUALES}

El presente trabajo está referido a la responsabilidad civil de quienes producen, distribuyen y comercializan productos y servicios destinados al consumidor, y que por sus defectos pueden resultar dañosos.

La primera delimitación afecta al campo de la responsabilidad involucrado, la responsabilidad civil, por lo que dejaré fuera del análisis las de carácter penal o administrativo de las cuales también pueden ser pasibles quienes dañan a consumidores.

La segunda delimitación se circunscribe a los sujetos y a los daños. No me interesa tratar todos los daños que pueda provocar la puesta en el mercado de un producto defectuoso, por ejemplo sobre la competencia, sino los daños que puedan afectar a la persona o bienes de los consumidores por efecto del "consumo" de esos productos o servicios defectuosos.

La tercera delimitación alude a que no me ocuparé de todos los daños que puedan afectar al consumidor por razón del producto defectuoso, por ejemplo los denominados daños intrínsecos del producto ocasionados por su desperfecto o malfuncionamiento. Estos quedan bien cubiertos bajo el sistema de garantías, antes que por el sistema de responsabilidad civil. Por ello me ocuparé de los daños que pueden afectar al consumidor en su vida, salud, integridad personal o sus bienes.

\section{DENOMINACIÓN DEL CAMPO DE ESTUDIO}

Con relación a la denominación de este campo de estudio también es conveniente hacer alguna precisión. Se lo designa en el common law, de donde es originario, como product liability, de allí que se lo haya traducido literalmente como responsabilidad del producto, pero 
se trata de una incorrección terminológica dado que el producto no es sujeto de derecho y por ende no puede tener responsabilidad, lo que si sucede es que el producto la genera, por ello es preferible hablar de responsabilidad por productos, o con más precisión responsabilidad por productos defectuosos (Payet, 1997).

Tallone (2002) se refiere a este campo como responsabilidad civil por productos elaborados, considerando a esa denominación correcta, aunque reconoce que también es abarcativa de los servicios. Igualmente se lo denomina Derecho de Daños por productos elaborados, cambiando la referencia a la responsabilidad civil, que al parecer es una denominación que va cayendo en desuso.

Kelly (1985) denomina a este segmento de la responsabilidad como responsabilidad del fabricante y habla de daños causados por productos elaborados, pero explica que es por una cuestión de comodidad dado que reconoce que no solo los fabricantes pueden ser responsables y no solo las cosas muebles elaboradas pueden generar la responsabilidad de la que se ocupa. No obstante al referirse al fabricante, o más correctamente productor, se quita el acento que la denominación debería poner sobre la victima del daño y no su agente causal.

Por lo expuesto considero más apropiada la denominación Derecho de Daños al consumidor o Responsabilidad civil por daños al consumidor por ser más abarcativa e incluir bajo ese rotulo también a los servicios.

Por otra parte la sola referencia al producto nos lleva a otro posible equívoco, y es que no discrimina en su denominación a la víctima del daño, que puede ser tanto el consumidor como algún componente de la cadena de distribución-comercialización. Esta distinción es necesaria porque, por ejemplo, si una botella que estalla en la mesa del consumidor y lo lesiona, no se rige por las mismas reglas que si estalla en la bandeja del mozo provocándole similares lesiones, y como veremos esta es una diferenciación que corresponde realizar. Por estas mismas razones también considero esta definición preferible a aquellas que aluden a los fabricantes o productores.

\section{LOS DAÑOS AL CONSUMIDOR}

Explica Alpa (2004, p.397) que "en la sociedad moderna es fenómeno habitual la propagación de daños vinculados con el proceso productivo". Es por ello que en materia de responsabilidad civil, se ha abierto un camino propicio a la consideración de los daños al consumidor como un capítulo autónomo. En un principio el tratamiento particularizado se generó a partir de los productos elaborados (o también de los productos dañosos o defectuosos), pero posteriormente este panorama se fue ampliando y actualmente abarca no solo a productos sino también a servicios.

La problemática de los daños al consumidor resulta compleja, máxime cuando el mismo resulta del vicio o defecto de un producto elaborado. 
En apretada síntesis lo expresan Kemelmajer de Carlucci y Parellada (1992, p.401) cuando explican que "en nuestra época la elaboración a nivel artesanal tiende a desaparecer, los productos llegan al consumidor final tras una larga cadena de proveedores de los diferentes elementos que los componen y de los consabidos intermediarios. La determinación del fabricante responsable se torna dudosa dada la gran cantidad de piezas elaboradas por distintos industriales que se reúnen para llegar al producto final. El desarrollo de la técnica no sólo va creando nuevas situaciones de peligro de daños sino que comporta una mutación en el modo en que éstos se producen porque en gran parte son anónimos; la figura del dañado sigue siendo cierta, en cambio la del agente se esfuma”.

Con el avance de la sociedad de consumo, el aumento de los daños ocasionados por productos elaborados puso de manifiesto la exigencia y la necesidad de una reglamentación específica para atender a este tipo de responsabilidad.

En principio, ante la ausencia de normas concretas y específicas, se producía una extrapolación a esta materia de la normativa prevista para otros tipos de responsabilidad. Pero esta "importación" de normas no siempre condujo a resultados satisfactorios, tanto por lo específico de la conducta que aquí se trata, como por la complejidad de aspectos jurídicos que esta clase de responsabilidad implica. Era necesario superar las normas generales del Código Civil, en sus limitaciones y disquisiciones, puesto que no estaban pensadas para la compleja problemática que nos ocupa. Adicionalmente el fenómeno de la globalización y la regionalización obligaban a estar atento a lo que sucedía allende las fronteras nacionales, también en este aspecto se ve con fuerza el ocaso del derecho nacional tradicional; ensimismado y atento en su propia realidad local.

Como explica Andorno (1997, p.651) "los daños originados por productos defectuosos han puesto de manifiesto, una vez más, la inadecuación de la disciplina tradicional de la responsabilidad civil, basada en la culpa como criterio fundamental de imputación del daño al responsable, para atender satisfactoriamente los nuevos supuestos de daños que de una u otra forma aparecen ligados al desarrollo industrial y tecnológico propio de la sociedad actual. Esos nuevos casos de daños pusieron de relieve, en efecto, que aplicando esa disciplina tradicional, la mayoría de las víctimas quedaba sin indemnización ante la dificultad de probar la culpa del causante del daño. Porque en esos supuestos, la culpa, si existe, se diluye, en cuanto el elemento humano pierde cada vez mayor relevancia en el mecanismo de producción del daño. La solución que con carácter general se ha arbitrado al respecto ha sido, como se sabe, la de consagrar supuestos de responsabilidad objetiva, en los que la existencia de la responsabilidad no depende ya de la culpa, proporcionando así a las víctimas de esos daños un responsable, facilitándose de esa manera su derecho a ser adecuadamente resarcidas".

\section{PARTICULARIDADES DE LOS DAÑOS POR PRODUCTOS}

Los daños ocasionados por los productos se caracterizan por la complejidad y masividad. 
La complejidad del bien tiene que ver con el desarrollo tecnológico, es decir, con los cambios que se han producido en los procesos de elaboración a partir de la evolución de la ciencia y la técnica, y hace que sea mucho más costoso para el consumidor acceder a información precisa y completa sobre las características del producto en cuestión, en consecuencia se profundiza la brecha en términos de conocimientos entre los contratantes y se acentúan las asimetrías.

Hasta principio del siglo XX los bienes que se comercializaban en el mercado eran simples, es decir, tecnológicamente no muy sofisticados, por lo que el consumidor podía determinar sus características -y conocer sus defectos- con relativamente bajos costos porque no le requería mayores conocimientos técnicos.

El otro fenómeno presente es la masividad que es un derivado de la masificación de la producción y el consumo, que hace que cada vez se produzca más para hacer frente al incremento del consumo de productos, a la vez más complejos y riesgosos.

Supongamos que el producto es el agente dañador, y como tal puede dar lugar a distintos tipos de afectaciones dañosas. Puede lesionar la integridad psicofísica o incluso la vida de una persona, en tal caso existiría una afectación a un derecho subjetivo individual que habilitaría la vía de un proceso judicial común, bilateral, contencioso, etc.

En el caso que el producto fuera ambientalmente toxico, altamente contaminante, no biodegradable, etc. existiría un daño al medio ambiente, a la ecología, es decir se estaría afectando un bien colectivo (no individual) sobre el cual no hay derechos subjetivos, ya que se trata de un bien indivisible y de uso común. En ese caso se concede a cualquier afectado, a una organización no gubernamental o a un organismo público, la legitimación para actuar como sujetos protectores del bien colectivo. Precisamente por ello, de existir una indemnización, la misma no puede ingresar al patrimonio del accionante sino que deben ser aplicada a reparar el daño del objeto en sí o en finalidades vinculadas a ese bien colectivo.

Finalmente, si el producto dañoso afecta la integridad psicofísica, la salud o la vida de miles de personas, estaríamos en presencia de la lesión de bienes individuales sobre los cuales recaen derechos subjetivos. Como se puede apreciar la diferencia entre el primer caso y éste, no es de naturaleza jurídica, ya que solo presenta una variación cuantitativa, pero plantea un problema muy concreto vinculado con la organización de la justicia que se necesita para hacer frente a miles de reclamos homogéneos. Esta cuestión tiene aristas enlazadas con el acceso a la justicia, los costos de la administración de la misma y los requerimientos de adecuación normativa para acoger estos fenómenos nunca antes vistos.

En resumen, en el primer caso se hallan en juego intereses individuales, en el segundo un interés colectivo que trasciende la esfera individual, y en el tercero intereses homogéneos pluriindividuales que pueden ser colectivos, difusos o públicos.

Como explica Ricardo Lorenzetti (2000, p.235) "los bienes individuales homogéneos permanecen en el campo de los derechos individuales, pero su masividad perturba un modelo pensado para administrar conflictos individuales. Los problemas en este campo son básica- 
mente de administración de justicia y orientados a garantizar el acceso de grandes grupos de dañados a una solución pronta y eficaz”.

Pero en particular cuando nos ocupamos de productos elaborados podemos apreciar que en la generalidad de los casos se trata de daños colectivamente causados, lo cual lleva la virtual imposibilidad de determinar quiénes son los causantes del mismo, lo que ha sido denominado anonimato en la causación.

En este punto corresponde una digresión, porque una reputada doctrina diferencia el Derecho privado individual del Derecho privado colectivo, encontrándose dentro de esta última categoría los problemas vinculados a bienes colectivos, pluri-individuales, o de grupos (Lorenzetti, 1995). En ese sentido manifiesta el autor que dentro del derecho privado colectivo distinguimos los daños colectivamente causados de los colectivamente sufridos. Dentro de estos últimos existen las categorías de daños a intereses transindividuales (colectivos y difusos) y pluriindividuales (daños masivos). Dentro de los daños masivos o colectivamente sufridos, se separan los accidentes masivos y los daños masivos. Los accidentes masivos envuelven situaciones en las cuales una cantidad de personas es dañada en un solo evento, como ocurre en un accidente de aviación o en la explosión de una bomba. En los de daños masivos, se presentan supuestos en los que no hay un solo evento, sino múltiples actos, problemas de causalidad, de competencia, de oponibilidad de eximentes, arribándose a litigios de gran masividad y alta complejidad de resolución.

Retomando la idea de los daños colectivamente causados, podemos apreciar la constitución de grupos de sujetos como agentes activos del daño y consecuentemente sujetos a la obligación legal de responder. En estos casos la pluralidad activa en la causación del daño puede presentarse de diversas formas, Tallone (2004, p.136) encuentra básicamente cuatro, a saber:

“a) Causalidad común: significa que hay una cooperación en la producción del daño. La causa no reposa en la actividad exclusiva de un sujeto, sino que cada participante opera en relación causal en pro del resultado. Se trata de una responsabilidad individual, en la que cada sujeto responde por el hecho de haber contribuido causalmente al resultado final.

b) Causalidad concurrente: aquí el daño tiene su origen en la acción independiente de dos o más personas, de manera tal que aun sin mediar el hecho de la otra el resultado igualmente se habría producido, no resultando posible su determinación.

c) Causalidad alternativa o disyuntiva: en este caso el perjuicio proviene de la conducta de un sujeto que integra un grupo, pero no resulta posible determinar cuál de sus integrantes fue el autor del daño. Es decir, estamos frente a diversos hechos que si bien poseen individualmente aptitud para provocar el resultado dañoso, éste ha tenido como antecedente a uno de ellos en forma exclusiva. De allí el carácter de alternativo o disyuntivo de la causa. La problemática gira en torno a la dificultad probatoria, que no permite señalar cuál de los integrantes del 
grupo resulta ser el autor del daño. La autoría se reputa anónima y la imputación deriva en grupal.

d) Causalidad grupal: el hecho se atribuye al grupo y no resulta posible que el daño lo produzca un individuo en forma aislada. A diferencia de los anteriores, en este supuesto la autoría y la imputación es grupal”.

De los cuatros modos de causar daños colectivamente, los dos últimos constituyen fenómenos de reciente aparición y con una enorme incidencia en la responsabilidad por daños al consumidor. Sin dudas el caso paradigmático trata de un daño ocasionado por un agente no identificado o de muy difícil individualización, que pertenece a un grupo circunstancial determinado (Taraborrelli, 1997).

Un caso típico de masividad y anonimato fue lo sucedido en EEUU en la década del '70 por el uso de la droga Diethylstilbestrol (DES). Se trataban de daños ocasionados por productos farmacéuticos, que se hicieron patentes varios años después de producida la ingesta de los mismos y cuando además no podían ser identificados los autores por haberse desechado los envases respectivos.

La DES estaba prescripta como un medicamento idóneo para evitar abortos espontáneos. No obstante luego se comprobó que producía un efecto colateral no deseado, cáncer en el cuello del útero. En 1971 dejó de fabricarse, pero para 1977 se calculaba que más de tres millones de mujeres padecían el tipo particular de cáncer que producía el DES. Ante la dificultad de determinar con precisión qué laboratorio debía indemnizar a cada quién, y la posibilidad cierta de dejar a las damnificadas sin reparación, la Corte de California elaboró la teoría del market share (participación en el mercado), por la cual cada laboratorio debía responder ante las víctimas según la proporción de su participación en el mercado al momento de haberse ocasionado el daño.

La visión tradicional en materia de responsabilidad civil no reparó en el problema de la masividad, el paradigma vigente solo admitía a un dañador y una víctima, en torno a litigios de daños producidos entre individuos concretos. Evidentemente se preveían casos de solidaridad, pero que en nada cambiaban la visión individualista, porque jamás se admitía a los sujetos como pertenecientes a grupos determinados y como explica Zabala de González, "el elemento colectivo del derecho de daños no es una realidad cuantitativa sino cualitativa" (1989, p.437).

También en la visión tradicional se consideraba que el daño era básicamente un accidente, ello es, un suceso casual, contingente, circunstancial e imprevisto. Por lo que proyectar daños o prever su ocurrencia era una tarea impensable, propia de adivinos y no de juristas. En cambio, muchas veces los daños ocasionados con productos poseen patrones de ocurrencia que pueden ser pronosticados estadísticamente -de hecho estos datos son tomados por los productores para decidir si resulta menos costoso prevenir los daños o indemnizarlos una vez producidos, como sucedió en el caso del Ford Pinto- y ello debe tener una incidencia decisiva en las reglas de responsabilidad. 
Finalmente, bajo el paradigma decimonónico se percibía a la responsabilidad civil como una cuestión bipolar, por un lado dañador(es) y por el otro víctima(s), no se reparaba en su carácter social. La teoría clásica era muy estricta en esa visión, y consideraba posible incorporar unidades adicionales en cada polo (solidaridad activa o pasiva) sin que la ecuación sufra alguna variación significativa. De hecho podía existir una alteración cuantitativa pero nunca cualitativa, dado que las propiedades caracterizantes de la responsabilidad permanecían invariables.

Vimos que la masividad produjo perturbaciones a esa lógica, obligando a brindar soluciones innovadoras para atender nuevas situaciones. No obstante, el planteo de fondo seguía siendo de corte individualista, porque el universo de la responsabilidad se reducía a dañadores y dañados. También ese status quo vino a ser desafiado por la responsabilidad por daños al consumidor.

Es imposible referirse a este ámbito de la responsabilidad concentrándose solamente en agentes causales del daño (productores) y victimas (consumidores). En virtud de su incidencia sobre el sistema económico, es dable analizar las soluciones propuestas en consideración a todo el universo de productores y consumidores, evaluando los incentivos y desincentivos que se crean sobre actividades económicas concretas y en definitiva analizar el régimen de responsabilidad en función de su capacidad de alterar la estructura económica de una sociedad y los modos de circulación de la riqueza.

En pocas palabras esta responsabilidad deja de ser territorio exclusivo de dañador y víctima, para ser un espacio de interacción social con derivaciones muy extendidas, que deben ser incluidas en los análisis de la materia. También en esto la responsabilidad por daños al consumidor difiere de las teorías tradicionales que usualmente se desentienden de los análisis consecuencialistas.

\section{EVOLUCIÓN DEL RÉGIMEN DE RESPONSABILIDAD POR DAÑOS AL CONSUMIDOR. LOS ANTECEDENTES EN EL COMMON LAW}

Desde el punto de vista estricto de los antecedentes de la responsabilidad civil por productos elaborados, el núcleo de su desarrollo no se encuentra en el civil law continental sino en el common law anglosajón, principalmente estadounidense.

Como era de esperarse su desarrollo provino del devenir jurisprudencial, que le permitió ir adecuando paulatinamente las soluciones jurídicas a las necesidades y realidades sociales.

Como afirma Salvador Coderch (2003, p.5) "las reglas contemporáneas de la responsabilidad civil de producto surgen en torno al derecho de la responsabilidad contractual, se encuentran luego con el sistema de la responsabilidad por negligencia y confluyen finalmente en una única regulación de responsabilidad objetiva que combina elementos de ambos regíme- 
nes", así "antes de que la Revolución Industrial madurara y alcanzara un estadio de consumo masivo, la regla general en materia de responsabilidad contractual tanto en el civil law como en el common law era el principio de eficacia relativa de los contratos", es decir el principio jurídico por el cual se reconoce que los contratos solo producen efectos entre las partes y sus sucesores y no para terceros, esto es lo que los juristas anglosajones llaman privity of contract, por ello el damnificado tenía acción únicamente contra el fabricante si había comprado el producto directamente de él. Esta regla es en algo similar a la continental "res inter alios acta".

En un caso resuelto en la Gran Bretaña en 1842 en el marco del rule of privity, Winterbottom v. Wright (152 Eng. Rep. 402 (Ex. 1842)), un coche tirado por caballos fabricado por el demandado se accidentó como consecuencia de un defecto de fabricación resultando dañado un pasajero, que luego se constituyó en demandante. En esa oportunidad, la pretensión fue rechazada fundado en el hecho que no existía vínculo contractual entre el pasajero y el fabricante del coche. La resolución de este caso devino en regla general hasta bien entrado siglo XX. "La idea subyacente era que cada parte que configurara un eslabón en la cadena de contratos podría demandar por vicios ocultos a quien se hubiera relacionado contractualmente con él, pero no a un eslabón anterior" (Coderch, 2003, p.5). En dicho fallo podía leerse esta afirmación "no existe contrato entre las partes en el pleito; y si se permite al actor demandar, cualquier pasajero o incluso cualquier viandante, que fuera herido por el accidente del coche de caballos, podría entablar una acción similar. A no ser que se restrinja el alcance de estos contratos a las partes que los celebraron, las consecuencias más absurdas y horribles tendrían lugar".

En rigor de verdad, las repercusiones de este fallo fueron más allá de sus reales pretensiones. La regla que se pretendía consolidar es similar a lo que conocemos como los efectos no expansivos del contrato, es decir, las acciones referidas al incumplimiento contractual solo pueden ser iniciadas por los contratantes y no por terceros. No obstante ello, fue entendido en el sentido que el productor no responde por los daños causados a un no contratante, aún cuando el fabricante hubiese sido negligente en la elaboración del producto.

En esta línea de pensamiento mayoritaria, el fallo sirvió de barrera de contención para las pretensiones contenidas tanto en acciones contractuales como extracontractuales. Solo se hacían lugar a acciones de daños incoadas por los damnificados, en cuanto compradores, contra los fabricantes, en cuanto vendedores.

Lentamente se fueron corriendo los daños por productos del rule of privity (un equivalente a nuestra responsabilidad contractual) hacia el tort of negligence (un equivalente a nuestra responsabilidad extracontractual por culpa), básicamente a través de la creación de excepciones pero sin alterar la regla general que se mantenía incólume. Así llegamos al inicio del siglo XX cuando la excepción pasó a ser la regla.

En 1916 en los Estados Unidos se resolvió un verdadero leading case para la responsabilidad por productos, el caso MacPherson vs. Buick Motor Co. (111 N.E. 1050 (N.Y. 1916)), nuevamente nos encontramos frente a una situación originada por daños ocasionados por un coche aunque en esta ocasión a motor. En este caso se había producido un accidente el cual re- 
sultó herida una persona, cuando los rayos de una rueda de madera de un automóvil nuevo se rompió y el auto chocó. El lesionado accionó contra el fabricante del automóvil y el demandado alegó que el dueño del auto lo había comprado de un revendedor y que la rueda había sido fabricada por otra empresa. El tribunal acogió la pretensión contra el fabricante del automóvil y resolvió el caso aplicando las reglas de la responsabilidad por negligencia

Cabe la pregunta: ¿de dónde surge la culpa?, básicamente la situación era la siguiente, una persona compra a un vendedor (no fabricante) un automóvil; éste pierde una rueda y el comprador sale despedido. Ulteriores investigaciones demostraron que el defecto estaba en la rueda, pero ésta no había sido fabricada por el fabricante del automóvil sino por un tercero (autopartista). La víctima demanda al fabricante del automóvil y la pretensión es acogida fundada en el hecho que el defecto pudo ser descubierto por el fabricante mediante una razonable inspección que fue omitida y de allí su accionar culposo.

A partir de aquí el precedente MacPherson vs. Buick Motor Co. empezó lentamente a reemplazar Winterbottom $v$. Wright como regla general a la hora de tratar la responsabilidad del fabricante no vendedor. Pero esto tiene una explicación "Inglaterra había sido pionera en la Revolución Industrial, pero el consumo en masa surgió a inicios del siglo XX en los Estados Unidos de América, primera sociedad en la cual bienes de consumo duraderos y de tecnología compleja se comercializaron de forma masiva y fueron adquiridos por multitud de consumidores, ignorantes racionales de los riesgos de las máquinas que compraban" (Coderch, 2003:7).

En 1944, también en los Estados Unidos, se ventiló el resonante caso Escola vs. Coca Cola Bottling Co. of Fresno (15o P.2d 436 (Cal. 1944)). En esa oportunidad una camarera (no un consumidor) sufrió lesiones al explotarle una botella de Coca Cola en la mano al introducirla en una heladera. La demandante alegaba que la empresa había sido negligente al llenar el envase a excesiva presión o bien el mismo recipiente era defectuoso y de allí el estallido en una situación de manipuleo ordinario. La pretensión fue acogida favorablemente aunque la mayoría del tribunal aplicó la doctrina del la res ipsa loquitur en función de la cual la negligencia (culpa) se presume, pero un voto particular, del Juez Traynor, empezó a abrir camino en una diferente dirección al fundar el deber de reparar en un régimen de responsabilidad objetiva por defectos del producto. Con el tiempo este voto en particular se convirtió en la ratio decidendi de la mayor parte de las jurisdicciones estadounidenses.

De todos modos los jueces todavía seguían requiriendo la prueba de la negligencia del fabricante. Esa era una prueba difícil que obligaba a los litigantes a buscar el atajo de las garantías, en un primer momento explícitas (express waranty) y luego implícitas (implied warranty). De esta forma la acción seguía basándose en una obligación de naturaleza contractual por la cual el fabricante ante todo garantizaba la seguridad del producto.

La verdadera consagración del camino abierto por Escola v. Coca Cola Bottling Co. of Fresno se dio con el fallo Hennington vs. Bloomfield Motors (32 N.J. 358, 161 A 2 d 69 (1960)). El caso se trataba del accidente de una persona causado por la falla de la dirección de un automóvil. La responsabilidad se imputa a titulo objetivo, aunque todavía en el ámbito contractual. En esa 
sentencia, termina por ser invalidada la regla de la privity of contract, y el requisito de la garantía implícita se extiende a todos los productos y no sólo a los alimentos como en un principio.

Posteriormente se resuelve el caso Greenman vs. Yuba Power Products (59 Cal. 2d, 27 Cal. Rptr. 697, 377 P. 2 d 897 (1963)) donde se ventila una situación de daños sufridos por una persona que había utilizado una herramienta multifunción que podía servir de sierra, taladro y torno de madera. Mientras el damnificado trabajaba con la herramienta, una pieza se soltó por fallas en los tornillos de sujeción y le causó serios daños en el rostro.

En este caso se rompe definitivamente con la anterior lógica y se admite una acción basada en tort (el equivalente a nuestra responsabilidad objetiva extracontractual) y no el contract, por lo que no había que cumplir ningún requisito de privity. El daño causado por un producto elaborado deja de ser un daño contractual para pasar a ser un daño extracontractual, pero con esta novedad: el factor de atribución es la responsabilidad objetiva (strict product liability in tort). En el fallo puede leerse "el productor es objetivamente responsable, si difundiendo un producto sobre el mercado, con el conocimiento que este será usado sin ningún control preventivo, el producto resulta peligroso para la salud humana" (Alpa, 2004, p.404).

Como afirma Payet (1997), la responsabilidad extracontractual estricta por productos defectuosos (strict product liability in tort), es fruto de la evolución de la responsabilidad civil por culpa (tort of negligence) y el régimen de garantías expresas (express waranty) y tácitas (implied warranty).

Con posterioridad, en 1965, fue codificado en artículo 402 A del Restatement of Torts (Second), a partir del cual la responsabilidad civil por defecto de producto era imputado a título objetivo, independiente del contrato, y abarcaba también al vendedor de manera solidaria.

Esta consagración legislativa fue de particular importancia en el derecho comparado porque "la regulación europea vigente sobre la responsabilidad objetiva del fabricante por defecto del producto se inspira claramente en los desarrollos jurisprudenciales norteamericanos y, en particular, en el Restatement de 1965" y de allí se construyó un puente con el resto del sistema continental del civil law.

\section{EVOLUCIÓN DEL RÉGIMEN DE RESPONSABILIDAD POR DAÑOS AL CONSUMIDOR EN EL DERECHO CONTINENTAL}

Los dos grandes ejes del debate pasaban por el ámbito de la responsabilidad (contractual o extracontractual) y su imputabilidad (subjetiva u objetiva).

En primer término se discutía si la reparación del daño había operado en virtud del incumplimiento de una obligación de origen contractual, o fuera de ese ámbito en el contexto de la violación de un deber general de no dañar. Recordemos que la teoría decimonónica tradicio- 
nal, principalmente de fuente francesa, era muy estricta en la separación de estos dos ámbitos de la responsabilidad, estableciendo regímenes bien diferentes para cada caso.

Con relación a los daños por productos, era clara la solución para el supuesto del consumidor-comprador con relación al fabricante-vendedor, pero en otros supuestos el principio de los efectos relativos del contrato impedía al consumidor accionar contra el fabricante no vendedor.

Para subsanar las injusticias que generaba el sistema, tanto tribunales como doctrinarios, empezaron a hacer uso de construcciones jurídicas que técnicamente hablando eran verdaderas distorsiones de las instituciones tradicionales y así se hablaba de los contratos tácitos, la cadena ininterrumpida de contratos, contrato a favor de un tercero, negocio fiduciario, cesión de créditos, acción directa, acción subrogatoria, relaciones contractuales fácticas, obligación de garantía, etc., por la cual, en definitiva, se buscaba dar una solución basada en la responsabilidad contractual a situaciones en la cuales no existía contrato, pero que de situarse en el ámbito de la responsabilidad extracontractual hubiese quedado sin cobertura.

Como corolario, ningún intento de fundar el régimen de reparación de los daños causados por productos en un sistema de responsabilidad contractual fue satisfactorio, cada recurso ad hoc generaba un nuevo problema, porque en definitiva lo que existía era una inadecuación de la respuesta normativa a esta nueva problemática. Paralelamente la tesis dualista estricta entró en crisis en el siglo XX, y fue siendo reemplazada por un sinceramiento en las soluciones jurídicas, que sin llegar el monismo, reconocía que se trataban de espacios diferentes pero con muchos puntos en común. En ese sentido las diferentes legislaciones fueron manteniendo algunas diferencias en la extensión del resarcimiento, período de prescripción, validez de cláusulas de exclusión de responsabilidad, etc.

En ese contexto, desde el Derecho del Consumidor se presentaron soluciones específicas, que se pusieron por encima de esta discusión unificando el régimen de daños por productos, pero básicamente sobre una base extracontractual.

Desde el punto de vista de la imputabilidad, Nicolau (1995) reconoce tres grandes unidades temporales en la evolución de la teoría de la responsabilidad civil en la familia jurídica occidental, un período primitivo que va desde las incipientes manifestaciones jurídicas hasta el Derecho Romano clásico, un período intermedio desde el Derecho Romano clásico hasta el Siglo XX y finalmente un período contemporáneo que abarca todo el siglo pasado hasta los tiempos presentes.

En el Derecho primitivo no existía una clara distinción entre responsabilidad civil y penal, a la vez que la imputación básica era a titulo objetivo, es decir que una vez aparecido un daño se imponía la aplicación de una pena sin reparar muchas veces en los factores de atribución (Alterini y Lopez Cabana, 1995).

En estas épocas primitivas la respuesta ante el daño era la venganza, irracional y desproporcionada. No era un dato significativo la calidad o cuantía del daño, ni la voluntariedad (culpa) del ofensor. Ante el daño el hombre reaccionaba irracionalmente sin distinguir su fuente, ante el dolor y cólera causado por el daño, este debía ser expiado de cualquier forma para 
morigerar sus consecuencias (Nicolau, 1995, ps. 45-46). Pero la venganza era simplemente una forma de purgar el daño causado, no una forma de reparación, por ello "[n]o se investiga el nexo causal entre el daño y la conducta y tampoco se trata de sancionar una conducta ilegítima” (Idem, 46).

En una ulterior evolución se morigeró la venganza total sometiéndola a alguna forma de limitación, en este sentido la fórmula de la ley del Talión "ojo por ojo y diente por diente" representó un avance significativo.

Posteriormente, en muchos casos este mecanismo fue reemplazado por la composición voluntaria o legal, a partir de la cual la víctima se cobra sobre el patrimonio del ofensor y no sobre su persona resultándole esto más conveniente económicamente.

La imputación era puramente material u objetiva, aun los animales y las cosas inanimadas debían responder del daño que habían causado. Se trataba de un sistema que se desentendía de la víctima y del autor del daño.

En el período intermedio se avanza en la comprensión del daño, se empieza por ejemplo a distinguir las fuentes de estos (los provenientes de hechos del hombre y de la naturaleza), se empieza a observar el nexo causal y la idea de reparación empieza a cooptar la noción de venganza, pero la imputación del daño continuaba siendo básicamente objetiva, en este sentido los romanos entendían que "su estructura jurídica descansaba sobre la idea de que en el origen de la sociedad existió una repartición equilibrada de los patrimonios, cuyo equilibrio importaba mantener a fin de preservar el orden y la paz social. De tal modo, cualquier daño sufrido por un patrimonio debía ser reparado por el patrimonio que la hubiera causado" (Ídem, 48).

En los estadios más avanzados del Derecho Romano Clásico, pero principalmente por influjo del Derecho Canónico, se desarrolló la teoría de la culpa como fundamento principal de la responsabilidad civil. Era una forma de unificar la reprochabilidad moral de la conducta con el deber de reparar, por lo que a esta concepción se le reconocía un notable valor ético intrínseco. Observemos que "la imputación moral en razón de la culpabilidad exige una penetración anímica del sujeto, y conduce al examen de lo interno del obrar" (Alterini y Lopez Cabana, 1995, p.157), así se condenaba solo a quien dañaba a través de su obrar doloso o negligente.

Esta fórmula contaba además con un adicional que lo tornó atractivo a los ojos de los juristas liberales del siglo XIX, su marcado individualismo, por lo que fue consagrado como principio en todos los Códigos de su tiempo. A esto debiéramos sumarle que también fue un instrumento de fomento para la incipiente industria desde el momento que suponía una reducción de costos al eximir al empresario del daño producido sin mediar culpa de su parte.

Este sistema, que en la teoría implicaba unificar las reprochabilidades jurídica y moral en un mismo sujeto a partir de la exigencia de la culpabilidad, resultó ser demasiado estrecho y aun injusto en determinados casos. Como señala Farina, transformar el principio "ninguna responsabilidad sin culpa" en un axioma del sistema de responsabilidad civil, como sucedió en 
el siglo XIX y parte del XX, implicaba exonerar a las empresas por los daños y efectos nocivos que producían sus actividades riesgosas (Farina, 1997). De esa forma, lo que en un principio fue concebido como una especie de fomento, a la larga se transformaba en un subsidio encubierto a actividades inseguras (Lorenzetti, 1993).

Esta concepción subjetivista, observada desde la óptica del consumidor o cualquier otro sujeto dañado, no estaba lejos de generar un cúmulo de situaciones injustas al centrar su atención con exclusividad en la situación del autor del daño y no en quien resultaba víctima del mismo. En determinados casos, producido un daño injusto sin mediar culpa del agente, todos los costos del mismo debían ser soportados por la víctima, esto motivó que se empezara a morigerar la situación a través del principio de equidad.

Mientras tanto en Francia comenzó a abrirse camino la denominada teoría del riesgo que hicieran célebre Saleilles y Josserand, "cuyo paradigma de imputación estriba en atribuir el daño a todo el que introduce en la sociedad un elemento virtual de producirlo" (Alterini, 1976, p.106).

En toda Europa la revolución industrial, caracterizada por el maquinismo y la producción en gran escala, produjeron una marcada transformación en las condiciones económicas y sociales, tornando inadecuados los esquemas clásicos de la concepción subjetivista en materia de responsabilidad civil.

Para esta teoría es viable prescindir de la subjetividad del agente, desde el momento que "centra el problema de la reparación y sus límites en torno de la causalidad material, investigando tan sólo cual hecho fuera, materialmente, causa del efecto, para atribuírselo sin más" (Ídem), entonces resulta suficiente la trasgresión objetiva que se verifica a través de la lesión del derecho subjetivo ajeno.

Para esta teoría se rompe con la ecuación: "responsable igual a culpable”. Porque como señala Pizarro (1983, p.707) "quien introduce un factor generador de riesgos en la comunidad apto para causar daños a terceros, debe reparar los detrimentos que la misma produzca, aunque no haya mediado culpa alguna de su parte". En estos casos la ley imputa normativamente a un sujeto la obligación de reparar prescindiendo de culpabilidad alguna, atento a la relación causa-efecto en función de un riesgo creado por el agente. Es decir se está ante un daño atribuible materialmente a un agente en función de la cosa o actividad riesgosa que éste ha introducido en la sociedad.

De esta formulación se deduce que el agente responsable sólo puede eximirse de responsabilidad demostrando que la causa le ha sido ajena, que se ha roto la cadena causal, ya sea por la existencia de caso fortuito, culpa de la víctima, o intervención de un tercero por quien no debe responder.

A partir de la introducción de este precepto todo dueño o guardián de cosas pasa a responder por el solo hecho de causar el daño, sin que le sea suficiente probar para eximirse que de su parte no hubo culpa o que cumplió con todas las diligencias a su cargo.

Como advierte Rivera (1997, p.11) “durante mucho tiempo, los autores y sobre todo los civilistas, los abogados y los jueces han considerado que la función del sistema de responsa- 
bilidad civil es la atribución de una responsabilidad, de un castigo al autor de un hecho ilícito que hubiera sido susceptible de ser atribuido a él en función del dolo o de la culpa en que había incurrido y del cual había emanado un daño", pero "a partir de que a fines del siglo XIX la doctrina elabora los factores objetivos de atribución, particularmente la teoría del riesgo, hay todo un traspaso de la idea del derecho de la responsabilidad como atribución, como un castigo, como un juicio de reproche moral al autor del hecho ilícito (Llambías), hacia una concepción totalmente distinta, que pone su centro de mira en la víctima y por lo tanto se convierte en un sistema de reparación de infortunios".

La culpa ha pasado de ser el sistema prevalente, la regla de responsabilidad por antonomasia, a constituirse en los que el autor italiano Sandro Schipani denomina la "norma de clausura" del sistema de responsabilidad civil. Es decir primero debemos estar al factor de atribución consagrado por la ley para el caso específico, en defecto del cual recién podremos abrevar en la culpa como regla genérica (Alterini, 1997, p.122).

En el contexto de la crisis de la culpa empiezan a aparecer los daños por productos elaborados y a plantear nuevas problemáticas que no pueden ser resueltas del mismo modo que en el common law.

El derecho de daños al consumidor, no aparece en nuestras latitudes como un capítulo autónomo de la responsabilidad civil o a partir de desarrollos jurisprudenciales bien localizados como en el common law, sino como uno de los temas que abarcaba una nueva rama del derecho denominada Derecho del Consumidor.

El Derecho del Consumidor se presenta como un microsistema con una lógica interna propia, distinta a las instituciones jurídicas tradicionales, porque de hecho se vale de la crisis de éstas para hacer su aparición. En lo que respecta al derecho de daños, se aprovecha de los cuestionamientos que venían sufriendo los paradigmas tradicionales, como la utilidad de la división entre responsabilidad contractual y extracontractual, y la culpa como eje de la imputación. En tal sentido posiciona un régimen de responsabilidad único, aunque de base extracontractual, y establece un factor de atribución objetivo.

Para concluir puedo afirmar que en las últimas décadas se han registrado importantes cambios en el ámbito de la responsabilidad civil, se fueron superando las barreras de la tesis dualista que separaba radicalmente a la responsabilidad contractual de la extracontractual, también se ha ido sustituyendo la imputabilidad asociada básicamente al reproche, para hacer lugar a un sistema que apunta a la distribución de daños injustamente sufridos sobre la base de una diversidad de factores de atribución, y ello en consonancia con la colocación de la víctima en el centro de atención, preocupándose no solo de su reparación integral en caso de daño, sino también de la prevención del mismo. 


\section{ESTADO ACTUAL DE LA RESPONSABILIDAD POR DAÑOS AL CONSUMIDOR}

Más allá de particularidades, es posible identificar como elementos las siguientes propiedades caracterizantes del régimen por daños al consumidor:

- Hoy la responsabilidad por daños al consumidor está reconocida en el todo el mundo, justificándose su existencia en las particularidades que presentan los productos y servicios. Puntualmente se reconoce que la complejidad y masividad de dichos productos hace necesaria la existencia de reglas propias, diferentes a las del régimen general y a otros regímenes especiales.

- En todos los casos se verifica un apartamiento de las reglas generales sobre responsabilidad contractual y extracontractual.

- El sujeto protegido siempre es el consumidor (sea o no contratante), excluyéndose del régimen especial a otros sujetos como integrantes de la cadena de producción-distribución-comercialización.

- El régimen de responsabilidad establecido para atender los daños al consumidor es único, aunque de base extracontractual, y reconoce un único factor de atribución objetivo con un sistema de solidaridad de los agentes que integran la cadena de producción, distribución y comercialización.

- Imposibilidad de exoneración del productor probando su actuación diligente.

- En general el régimen de daños al consumidor abarca a todo tipo de productos y servicios, esto se ha consolidado con la nueva directiva europea, la 99/34/CE que viene a modificar la 85/374/CEE, en razón de la cual ya no se excluyen los productos agrícolas.

- También en general el régimen de daños al consumidor es amplio y en tal sentido abarca a todo tipo de daños, producido por todo tipo de productos y servicios, y comprende tanto a los patrimoniales y morales, como a los corporales y materiales.

- Hoy es entendida la responsabilidad por daños al consumidor como una parte del "estatuto" del consumidor, en tal sentido una línea directriz de esa rama del Derecho es asegurar la inocuidad de los productos y servicios, ante todo previniendo la producción de daños. La esencia del Derecho del consumidor es la prevención como sistema de protección y ello lo separa del derecho de responsabilidad tradicional que solo reacciona frente al daño ya producido.

\section{PROSPECTIVAS}

Si bien la prospectiva es una forma de mirar y anticipar el futuro, no se trata de hacer profecías sino de explorar los potenciales desarrollos futuros a partir de tendencias consolidadas, cuyo devenir no ha llegado todavía a un momento conclusivo. 
Las tendencias que podemos identificar y presentar como problemas actuales sin solución definitiva, son las siguientes:

- Debilitamiento del nexo de causalidad como presupuesto de la responsabilidad por daños al consumidor. En tal sentido podremos ver un reforzamiento del "market share" o construcciones similares, y su "exportación” a otros sistemas jurídicos distintos al common law. - Reconocimiento generalizado de las acciones de clases (class actions) como una forma de facilitar a los perjudicados el acceso a la justicia y garantizar soluciones homogéneas. - Aparición de los daños punitivos en los Derechos de tradición civil law.

- Inclusión de reglas comunes en espacios de integración regional a efectos de brindar protección uniforme a todos los consumidores, y evitar la aparición de barreras no arancelarias que obstaculicen la libre circulación de mercancías.

- De verificarse una retracción del sistema, seguramente la misma se haría efectiva a través de la tarifación de las indemnizaciones y/o la exclusión de la reparación del daño moral, reducción de los sujetos pasivos (por ejemplo eliminando a los distribuidores), y disminución de los tiempos legales para la presentación de reclamaciones (período de prescripción de la acción a contar desde la llegada del producto a manos del consumidor). En los EEUU existe un extenso debate en torno a estos temas y desde finales de los años '70 ya se habla de la crisis de la responsabilidad por productos por las consecuencias negativas que un sistema de reparación muy "liberal" tiene sobre actividades socialmente valiosas, pero con un riesgo por encima del promedio.

- Consolidación de la problemática de los riesgos del desarrollo. Los riesgos del desarrollo tienen que ver con la puesta en el mercado de bienes con defectos que fueran identificables posteriormente, a partir del avance de los conocimientos científicos y técnicos. En Europa por la Directiva 85/374/CEE, los riesgos del desarrollo funcionan como exclusión de responsabilidad del productor si "en el momento en que el producto fue puesto en circulación, el estado de los conocimientos científicos y técnicos no permitía descubrir la existencia del defecto", no obstante la misma norma permite flexibilizar su contundencia. De hecho cuando se produce un daño derivado de estos riesgos, algunos ordenamientos jurídicos imputan la responsabilidad correspondiente al fabricante del producto en cuestión, pero otros le conceden una excepción que le permite exonerarse de tal responsabilidad. Ocuparse de esta cuestión daría lugar a un trabajo diferente, dado que presenta aristas y consecuencias de las más variadas, y aquí solo podemos referir que está lejos de alcanzarse consensos en torno a la mejor solución a esta problemática y que seguramente pronto estaremos viendo instalado el debate también en los países latinoamericanos que hasta el momento han permanecido un tanto al margen de su tratamiento. 


\section{REFERENCIAS BIBLIOGRÁFICAS}

Alpa, Guido. (2004). Derecho Del Consumidor. Gaceta Jurídica. Lima.

Alterini, Atilio y López Cabana, Roberto. (1995) Responsabilidad Civil. Dike. Medellín (Colombia).

Andorno, Luís. (1997) “Responsabilidad Civil Por Productos Elaborados”, En Jurisprudencia Argentina 1997-III-651.

Diez-Picazo, Luís. (1999). Derecho De Daños. Civitas. Madrid.

Kelly, Julio Alberto. (1985). Responsabilidad Del Fabricante. Heliasta. Buenos Aires.

López Olaciregui, José María. (1978). “Esencia y Fundamento de la Responsabilidad Civil”, en Revista del Derecho Comercial y de las Obligaciones $N^{o}$ 2, Buenos Aires, 1978. Reimpresión en Revista de Responsabilidad Civil y Seguros $N^{o}$ 1; La Ley, Enero-Febrero 1999.

Lorenzetti, Ricardo Luis y Schötz, Gustavo Juan (Coordinadores). (2003). Defensa Del Consumidor. Ábaco. Buenos Aires.

Lorenzetti, Ricardo. (1995). Las Normas Fundamentales De Derecho Privado. Rubinzal Culzoni. Santa Fe.

Mosset Iturraspe, Jorge (Director). (1992). Responsabilidad Civil. Hammurabi. Buenos Aires.

Nicolau, Noemí. (1995). "Panorama de la Responsabilidad Civil en el Derecho Occidental: Retrospectiva y Tendencias”, en La Responsabilidad, Homenaje El Profesor Isidoro Goldemberg. Abeledo Perrot. Buenos Aires.

Parra Lucan, María Ángeles. (1990). Daños Por Productos Y Protección Del Consumidor. Bosch. Barcelona.

Payet, José Antonio. (1997). La Responsabilidad Por Productos Defectuosos. Pontificia Universidad Católica Del Perú. Lima. 
Salvador Coderch, Pablo Et Al. (2003) "Responsabilidad Civil del Fabricante y Teoría General De La Aplicación Del Derecho (Law Enforcement)" En In Dret, Working Paper No: 164. Barcelona, en www.indret.com

Tallone, Federico. (2002). Daños Causados Por Productos Elaborados. Hammurabi. Buenos Aires.

Vallespinos, Carlos Gustavo (Director). (1997). Responsabilidad Civil. Presupuestos. Advocatus. Córdoba.

Vázquez Ferreyra, Roberto y Romera, Oscar. (1994). Protección Y Defensa Del Consumidor. Depalma. Buenos Aires.

\section{CURRICULUM VITAE}

\section{Cristian Ricardo A. Piris}

Abogado. Magister en Derecho Privado. Doctor en Derecho. Profesor por concurso de la Universidad Nacional del Nordeste (Corrientes-Chaco. Argentina). Docente-Investigador categorizado (Ministerio de Educación de la Nación Argentina).

cristian.piris@gmail.com 